\title{
Antibiotic Resistance Patterns and Evaluation of Treatment of Inpatient with Urinary Tract Infections in Two Tertiary Care Hospitals at Kathmandu Valley
}

\author{
Pharsuram Adhikari ${ }^{1, *}$, Dharma Prasad Khanal ${ }^{2}$ \\ ${ }^{\prime}$ Department of Pharmacy, Purbanchal University College of Medical and Allied Health Sciences, Goathgaon, Biratnagar, NEPAL. \\ ${ }^{2}$ Department of Pharmacy, Manmohan Memorial Institute of Health Sciences, Tribhuvan University, Soalteemode, \\ Kathmandu, NEPAL.
}

\section{Received: 09 February 2020 \\ Accepted: 02 April 2020 \\ *Correspondence to: \\ Pharsuram Adhikari,}

Purbanchal University College of Medical and Allied Health Sciences, Goathgaon-56600, Biratnagar, NEPAL

Email: pharsuramadhikari@gmail.com Copyright: (C) the author(s),publisher and licensee Indian Academy of Pharmacists. This is an open-access article distributed under the terms of the Creative Commons Attribution Non-Commercial License, which permits unrestricted non-commercial use, distribution, and reproduction in any medium, provided the original work is properly cited.

\begin{abstract}
Urinary tract infections (UTIs) is a common bacterial infection in humans of all ages but the prevalence increases with increased age. It is one of the most common types of community and hospital acquired infections. It is a common cause of infections among young, sexually active women; an estimated 1 in 3 women will develop a urinary tract infection before the age of 24 years. Escherichia coli are the leading cause of UTI in humans. It is one of the most common pathogen isolated in around $75 \%$ of uncomplicated UTI. It is a growing concern worldwide due to increasing rate of antimicrobial resistance. In Nepal, UTIs is also common disease among Nepalese population. According to the annual report of Ministry of health and population 2016/2017 morbidity of UTIs in Nepal was 3,16,711. The descriptive study was conducted in inpatient at $\mathrm{MMCH}$ and MMTH, Kathmandu, Nepal from 29th May to 31st August, 2018. The sample size was 200 with the inclusion criteria of provisional diagnosis of UTI and sent urine sample for culture. A descriptive study was designed by taking total 200 samples of UTI admitted in two hospitals MMCH and MMTH. Treatment of UTI before and after antibiotic susceptibility test was analyzed. Antibiotic susceptibility test was done with commonly used antibiotics. During the study period, total 200 patients were admitted with the provisional diagnosis of UTI, among them 57 (28.5\%) micro-organism isolated. Urinary tract infection was more common among females than males. E. coliwas the most commonly isolated organism. Urinary pathogenesis showed resistance to commonly used antibiotics like Amoxicillin followed by Ceftriaxone, Ofloxacin, Ciprofloxacin and Cotrimoxazole.
\end{abstract}

Key words: Urinary tract infection, E.coli, Antibiotic Susceptibility, Antimicrobial Resistance, Empirical therapy

\section{INTRODUCTION}

Urinary tract infections (UTIs) is a common bacterial infection in humans of all ages but the prevalence increases with increased age. ${ }^{[1]}$ It is one of the most common types of community and hospital acquired infections. It is define as a significant bacterium in the presence of a constellation of symptoms such as dysuria (painful urination), increase frequency and urgency supra pubic discomfort and cost vertebral angle tenderness. It is a common cause of infections among young, sexually active women. It is estimated that 1 in 3 women will develop a urinary tract infection before the age of 24 years. ${ }^{[2]}$ Infection may involve either only the lower urinary tract or both the upper and lower tracts. A study done in The United States showed that UTIs is a major source of morbidity and associated health care costs. ${ }^{[3]}$ The higher incidence of these infections and the need to start treatment before the results of antibiotic susceptibility test become available as empirical treatment. Escherichia coli are the leading cause of urinary tract infections in human. It is one of the most common pathogen isolated in around $75 \%$ of uncomplicated UTI. ${ }^{[4]}$ It is a growing concern worldwide due to increasing rate of antimicrobial resistance..$^{[5]}$
Antibiotic resistances (ABRs) is a normal evolutionary process. The overuse of antibiotics in hospitals and empirical treatment approach accelerated the processes where $A B R$ have emerge as a global health problem. ${ }^{[6]} \mathrm{ABR}$ is not only creating difficult to treat infection associated with high mortality, but also threaten major progress in modern medicine like major surgery and cancer (chemotherapy) as well as having social and economical impact. ${ }^{[7]}$ $\mathrm{ABR}$ is increasing frequently, which is challenge for health care System. Irrational use of antibiotics is considered to contribute unnecessarily increase the rate of resistance. ${ }^{[8]}$ The treatment of choice for short term therapy with Trimethroprim or Nitrofurantoin which is successful in over $80 \%$ of cases. Co-trimoxazole, Fluoroquinolones or Cephalosporins are not considered first choice of drugs. ${ }^{[9]}$

Antibiotic therapy is normally empirical for most of the case, urine analysis is not recommended and antibiotics susceptibility test or sensitivity test arrive after the beginning of therapy. Fluoroquinolones normally are not included as first line UTI therapies; however they are often used in uncomplicated UTI and considered as an alternative therapy. ${ }^{[1,4,10]}$ From the various study Nitrofurantoin, Norflaxocin, Gentamycin and Ciprofloxacin 
are considered appropriate for empirical treatment if suspected E. coli as causative organism. ${ }^{[5,6]}$

The frequently prescribed antibiotics in hospital and the community settings over the last decades have accelerated the ABR and Multi drug resistance (MDR) which become growing concern and challenges in developed and developing countries. ${ }^{[1]}$ Due to this region there is difficult to treat highly infectious disease, surgery, cancer and it also impact on social and economical status of the people.

In case of Nepal, UTI is also common disease among Nepalese population. According to the annual report of Ministry of Health and Population 2073/74(2016/2017) morbidity of UTI in Nepal was 3, 16, 711. ${ }^{[12]}$ In the various study done in Nepal show the higher rate of commonly used antimicrobial agents are resistance in isolates of uropathogens. ${ }^{[13-16]}$

In Nepal the ABR problem is significant public health burden. According to Nepal's national public health laboratory reported on resistance rate of E. coli from 2006 to 2010, ABR rate were above 50\% for all drug which were been tested which included from highest to lowest resistance was with Amoxicillin, Cefixime, Amoxicillin-Clavulanic acid, Ceftrazidime and Cefotaxime respectively. ${ }^{[16]}$ UTI is one of the most common infectious diseases in Nepal where E. coli was mostly isolated in urine sample, which was treated with antibiotics. ${ }^{[17,18]}$ WHO, ABR global report include data from Nepal on bacterial infection ABR rates of bacterial pathogens E. coli, which was one of the leading causes of premature mortality from infectious disease. This report also includes highly resistance antibiotics on E. coli was Fluoroquinolones (64\%) and third generation Cephalosprines 38\%). ${ }^{[17]}$ Study done in western Nepal isolates various Uropathogens that were Pseudomonas spp. and morgenella Morgani that were found to be $100 \%$ multidrug resistance. ${ }^{[18]}$

\section{MATERIALS AND METHODS}

\section{Study Design and Setting}

The descriptive study was conducted in inpatient at Manmohan Memorial Community Hospital (MMCH) and Manmohan Memorial Teaching Hospital (MMTH), a community based tertiary care hospital with 100 and 300 patients beds respectively in Kathmandu, Nepal from $29^{\text {th }}$ May 2018 to $31^{\text {th }}$ August, 2018. This one hospital is located at main city and another is located outside the main city of Kathmandu.

\section{Inclusion and Exclusion Criteria}

In this study, all patients admitted with the provisional diagnosis of UTI and sent for urine sample culture before the starting the empirical antibiotic were included. However, the patients already on antibiotics and discharge before culture report were excluded.

\section{Data collection and processing}

The data were obtained from the log book of urine culture at microbiology department and patient information; discharged medicine had collected from different department manually as well as from medical record department.

\section{Statistical Analysis of data}

Data regarding patient information, antibiotics prescribed before and after sensitivity test, bacterial isolates, their susceptibility to various antibiotics and other information were entered and analyzed using Statistical Package for Social Sciences (SPSS) version-23.0 and Microsoft office excel 2010. The results are presented in frequency and percentage.

\section{Ethical Approval}

Written approval was obtained from Institutional Review Committee of Manmohan Memorial Institute of Health Sciences (MMIHS) before starting the study. The approval was taken hospital director.

\section{RESULTS AND DISCUSSION}

\section{Age Distribution of Patient}

During the study period, total 200 patients were admitted with the provisional diagnosis of UTIs, among them 57 (28.5\%) was isolated microorganism. The Patients of the age between 21-30 years is higher (26\%) and in age between 41-50 years is lower (6.5\%). But 51-60 years patient is high compare to $41-50$ years because this may be occur due to Prostate in male and Vaginitis in female (Table 1).

\section{Sex of Patient}

Study show that the proportion of UTIs is higher in females (70\%) than males (30\%) (Table 2)

\section{Microorganism Isolated}

Out of 200 suspected patient's growth of microorganism occurred in 57 patients (28.5\%). Among the isolates E. coli (54.4\%) was found to be the most predominant organism fallow by Klebsiella species (22.8\%), Citrobacter species (8.8\%), Staphylococcus aureus (7.0\%), Staphylococcus saprophyticus (5.3\%) and Acinetobacter species (1.8\%) respectively (Table 3 ).

\begin{tabular}{|l|c|c|}
\hline \multicolumn{2}{|l|}{ Table 1: Age of Patient. } \\
\hline Age of the patients & Frequency $(\boldsymbol{n = 2 0 0 )}$ & Percentage (\%) \\
\hline 1-10 years & 15 & 7.5 \\
\hline $11-20$ years & 19 & 9.5 \\
\hline $21-30$ years & 52 & 26.0 \\
\hline 31-40 years & 30 & 15.0 \\
\hline 41-50 years & 13 & 6.5 \\
\hline 51-60 years & 26 & 13.0 \\
\hline 61-70 years & 16 & 8.0 \\
\hline$>71$ years & 29 & 14.5 \\
\hline Total & 200 & 100.0 \\
\hline
\end{tabular}

\begin{tabular}{|l|c|c|}
\hline \multicolumn{3}{|l|}{ Table 2: Sex of the Patient. } \\
\hline Gender & Frequency $(\boldsymbol{n = 2 0 0 )}$ & Percentage (\%) \\
\hline Female & 140 & 70.0 \\
\hline Male & 60 & 30.0 \\
\hline Total & 200 & 100.0 \\
\hline
\end{tabular}

Table 3: Microorganism isolated.

\begin{tabular}{|l|c|c|}
\hline Name of Microorganism & Frequency $\mathbf{(} \mathbf{n = 5 7 )}$ & Percentage (\%) \\
\hline Escherichia coli & 31 & 54.4 \\
\hline Klebsiella spp. & 13 & 22.8 \\
\hline Citrobacter spp. & 5 & 8.8 \\
\hline Staphylococcus aureus & 4 & 7.0 \\
\hline Staphylococcus saprophyticus & 3 & 5.3 \\
\hline Acinetobacter spp. & 1 & 1.8 \\
\hline Total & 57 & 100.0 \\
\hline
\end{tabular}




\section{Empirically Prescribed Antibiotics}

This study was conduct in inpatients therefore 100\% antibiotics was used among them empirically Ceftriaxone was prescribed in $76.5 \%$ cases and followed by Ceftriaxone/Sulbactam (11.5\%) (Table 4).

\section{Antibiotics Prescribed After Sensitivity Result.}

In this study, Cefixime (33.33\%) was frequently prescribed antibiotic after susceptibility test result, Cefixime and Clavulanic Acid (15.79\%), Gentamycin (12.28\%) and Nitrofurantoin (12.28\%) (Table 5).

\begin{tabular}{|l|c|c|}
\hline \multicolumn{3}{|c|}{ Table 4: Empirically Prescribed Antibiotics. } \\
\hline Name of Antibiotics & Frequency $(\boldsymbol{n = 2 0 0 )}$ & Percentage (\%) \\
\hline Ceftriaxone & 153 & 76.5 \\
\hline Ceftriaxone/Sulbactam & 23 & 11.5 \\
\hline Levofloxacin & 5 & 4.5 \\
\hline Piperacillin and Tazobactam & 3 & 3.5 \\
\hline Gentamycin & 9 & 2.5 \\
\hline Amikacin & 7 & 1.5 \\
\hline Total & 200 & 100.0 \\
\hline
\end{tabular}

\section{Table 5: Antibiotics Prescribed After Sensitivity.}

\begin{tabular}{|l|l|l|}
\hline Antibiotics Prescribed & No. of Patients $(\boldsymbol{n}=\mathbf{5 7})$ & Percentage (\%) \\
\hline Cefixime & 19 & 33.33 \\
\hline Cefixime and Clavulanic Acid & 9 & 15.79 \\
\hline Gentamycin & 7 & 12.28 \\
\hline Nitrofurantoin & 7 & 12.28 \\
\hline Piperacillin and Tazobactam & 5 & 8.77 \\
\hline Cefpodoxime and Clavulanic Acid & 4 & 7.02 \\
\hline Cefpodoxime & 3 & 5.26 \\
\hline Levofloxacin & 2 & 3.51 \\
\hline Ciprofloxacin & 1 & 1.75 \\
\hline Total & 57 & 100.00 \\
\hline
\end{tabular}

\section{Antibiotic Resistance Pattern}

In this study, $54.4 \%$ E. coliwas isolated in urine sample in which Amoxicillin (77.4\%) is highly resistance followed by Ofloxacin (54.8\%) and Ceftriaxone (51.6\%). From this study oral drugs Nitrofurantoin (83.9\%) was the drug of choice as isolated found to be susceptible to drugs. (Table 6)

UTI is one of the most common diagnosis diseases among the patient seeking medical treatment in a developing country like Nepal. As the global trends, this study also reveals the higher prevalence of UTI in female patients $(70 \%)$ than male patents $(30 \%))^{[2,9,19,20]}$ The emergences of high rates of antibiotics resistance in UTI causing bacteria become a public health concern worldwide. According to WHO global survey 2014, the high proportion of resistance to fluoroquinolones report for E. coli, which means, limitation of available oral treatment against common bacteria causing UTI. In that survey $64.3 \%$ of E. coli was resistance to fluoroquinolones in Nepal. ${ }^{[17]}$

Among the urinary isolates, E. coli $(54.4 \%)$ was the most common uropathogens followed by Klebiella spp. (22.8\%), Citrobacter spp. (8.8\%), S. aureus (7.0\%), S. saprophyticus (5.3\%) and Acinetobacter spp. (1.8). In the similar study carried out by Sah et al. was found E. coli $(56.9 \%)$, S.aureus (27.7\%), Enteriococcus (7.7\%), Acinetobacter spp. (3.1\%) and Klebsiella, Pseudomonas, Citrobacter spp. (1.5\%). ${ }^{[1]}$ Similar study done in various hospital of Nepal was found E. coli as the leading pathogen causing UTI. ${ }^{[22-25]}$

The prescribing pattern of antibiotics may vary from place to place and time to time. The Choice of drugs by the physician also varies in the prescribing pattern of antibiotics. This study was conduct in inpatients therefore 100\% antibiotics was used among them empirically Ceftriaxone was prescribed in $76.5 \%$ cases and followed by Ceftriaxone/Sulbactam (11.5\%) In the similar study done by Sah et al. at Gyanocology OPD, the empirically prescribed antibiotics was Nitrofurantoin, followed by Ofloxacin, Cefixime, Norfloxacin, Amoxicillin and Levofloxacin. ${ }^{[21]}$

In this study, Cefixime (33.33\%) was frequently prescribed antibiotic after susceptibility test result, Cefixime and Clavulanic Acid (15.79\%), Gentamycin and Nitrofurantoin (12.28\%). In the similar study done in TU,

Table 6: Antibiotics resistance with isolated microorganism.

\begin{tabular}{|c|c|c|c|c|c|c|}
\hline & $\begin{array}{c}\text { E.coli } \\
\% n=31\end{array}$ & $\begin{array}{c}\text { Klebsiella spp. } \\
\quad \% n=13\end{array}$ & $\begin{array}{c}\text { Citrobacter spp. } \\
\qquad \% n=5\end{array}$ & $\begin{array}{c}\text { S. aureus } \\
\% n=4\end{array}$ & $\begin{array}{c}\text { S. saprophyticus } \\
\% n=3\end{array}$ & $\begin{array}{c}\text { Acinetobacter spp. } \\
\qquad \% n=1\end{array}$ \\
\hline Ampicillin/ Amoxicillin* & 77.4 & 84.6 & 80 & 50 & 66.7 & 100 \\
\hline Cefixime & 35.5 & 23.1 & 100 & 50 & 0 & 100 \\
\hline Ceftazidime & 29 & 7.7 & 60 & 25 & 0 & 0 \\
\hline Ceftriaxone & 51.6 & 38.5 & 60 & 25 & 33.3 & 100 \\
\hline Ciprofloxacin & 48.4 & 30.8 & 40 & 75 & 0 & 100 \\
\hline Cotrimoxazole & 48.4 & 15.4 & 80 & 75 & 66.7 & 0 \\
\hline Ofloxacin & 54.8 & 15.4 & 80 & 0 & 66.7 & 100 \\
\hline Gentamycin & 16.1 & 7.7 & 80 & 25 & 0 & 100 \\
\hline Nitrofurantoin & 16.1 & 53.8 & 60 & 0 & 33.3 & 100 \\
\hline Amikacin & 16.1 & 7.7 & 20 & 50 & 0 & $\mathrm{~N} / \mathrm{D}$ \\
\hline Imipenam & 19.4 & 0 & 60 & 25 & 0 & 100 \\
\hline Meropenam & 0 & 0 & 20 & $\mathrm{~N} / \mathrm{D}$ & $\mathrm{N} / \mathrm{D}$ & 0 \\
\hline $\begin{array}{l}\text { Piperacillin and } \\
\text { Tazobactam }\end{array}$ & 6.5 & 7.7 & 0 & 25 & 0 & 0 \\
\hline Polymycin-B & 0 & 0 & 0 & $\mathrm{~N} / \mathrm{D}$ & 0 & 0 \\
\hline Vancomycin & 0 & 0 & 0 & 0 & 0 & $\mathrm{~N} / \mathrm{D}$ \\
\hline
\end{tabular}

*Ampicillin disc is used for testing susceptibility to Amoxycillin as well. (According to product leaflet Himedia) 
IOM by Sha et al. there was 4.10\% Cefixime and 36.70\% Nitrofurantoin was prescribed. ${ }^{[21]}$ There is no similarity because there is not any standard UTI treatment guideline in Nepal. So, it varies among physicians according to their knowledge and experience. Antibiotic used also varies from place to place and physician to physician due to lack of standard treatment guideline. ${ }^{[26,27]}$

In this study, $54.4 \%$ E. coli was isolated in urine sample in which Amoxicillin (77.4\%) was highly resistance followed by Ceftriaxone (51.6\%) and Ofloxacin (54.8\%). In the similar study done by Ansari et al. found that E. coli isolates tested exhibited resistance to ciprofloxacin was $77 \% 0^{[28]}$ but in this study the resistance of ciprofloxacin in E. coli was only $48.4 \%$.

From this study, for the oral drugs Nitrofurantoin (83.9\%) was the drugs of choice of physicians as per susceptibility test results. Similarly, for intravenous injection Gentamycin (83.9\%) was most effective, whereas Ampicillin was found to be less effective. In the similar study done by Khadka et al. found the similar result that Nitrofurantoin $(86.73 \%)$ was highly sensitive and Ampicillin (27.55\%) was low sensitive drug. ${ }^{[18]}$

\section{LIMITATION OF THE STUDY}

Although this was a hospital-based study with sample size limited to only 200 patients. The study included only inpatient of two tertiary hospitals. Further country wide research with large sample size and multicenter study is required to determine overall prevalence of UTI in the country. Implementation of standard treatment guidelines is advisable.

\section{CONCLUSION}

Urinary tract infections was more common among females than males. E. coli was the most commonly isolated organism from UTIs patients. Urinary pathogen showed resistance to commonly used antibiotics like Amoxicillin followed by Ceftriaxone, Ofloxacin, Ciprofloxacin and Cotrimoxazole. Antibiotics resistance has been a growing threat to the effective treatment of UTI. This result in reduced efficacy of antimicrobial drugs, making treatment ineffective, costly or even impossible in some cases. It seems that we are losing the reserve group of antibiotics for the treatment of UTI.

\section{ACKNOWLEDGEMENT}

We are grateful to MMIHS - IRC for the permitting us to conduct the research. We would like to express our deepest appreciation to MMTH and $\mathrm{MMCH}$ for the authority to grant us permission for data collection. Furthermore we would also like to acknowledge with much appreciation the crucial role of the clinical laboratory staff of the hospital to complete this study. We would like to make special mention to extend my heartiest gratitude towards our family

\section{CONFLICT OF INTEREST}

There are no conflicts of interest to disclose

\section{ABBREVIATIONS}

ABR: Antibiotics Resistance; E. coli: Escherichia coli; EDL: Essential Drug List; ESBL: Extended spectrum beta Lactamase; IOM: Institute of Medicine; MDR: Multi Drug Resistance; MMCH: Manmohan Memorial Community Hospital; MMIHS: Manmohan Memorial Institute of Health Sciences; MMTH: Manmohan Memorial Medical College and Teaching Hospital; N/D: Not Done; OPD: Out Patient Department; SPSS: Statistical Package of Social Science; TU: Tribhuvan University; UTI: Urinary tract infection, WHO: World Health Organization.

\section{REFERENCES}

1. Aguiar JP, DaCosta FA, Silva PC. Evaluation of Empirical Antibiotic Therapy for the Treatment of Community-Acquired Urinary Tract Infections (CA-UTI). Int Arch Clin Pharmacol. 2015;1:002.

2. Thapa P, Parajuli K, Poudel A, Thapa A, Manandhar B, Laudari D, et al. Causative agents and susceptibility of antimicrobials among suspected females with urinary tract infection in tertiary care hospitals of western Nepal. J Chitwan Med College. 2013;3(2):16-9.

3. Hilbert DW. Antibiotic Resistance in Urinary Tract Infections: Current Issues and Future Solutions. Urinary Tract Infections. In Tech. 2011;193-206. Available from: http://www.intechopen.com/books/urinary-tract-infections/antibiotic-resistance-inurinary-tract-infectionscurrent-issues-and-future-solutions

4. Baral P, Neupane S, Marasini BP, Ghimire KR, Lekhak B, Shrestha B. High prevalence of multidrug resistance in bacterial uropathogens from Kathmandu, Nepal. BMC Research Notes. 2012;5(1):38.

5. Kibret M, Abera B. Antimicrobial susceptibility patterns of $E$. coli from clinical sources in northeast Ethiopia. African Health Sci. 2011;11(S1):S40-5.

6. Aypak C, Altunsoy A, Duzgun N. Empiric antibiotic therapy in acute uncomplicated urinary tract infections and fluoroquinolone resistance: A prospective observational study. Annals of Clinical Microbiology and Antimicrobials. 2009;8(1):28.

7. Flores MAL, Jennifer NW, Michael C, Scott JH. Urinary tract infections: Epidemiology, mechanisms of infection and treatment options. Nat Rev Microbiol. 2016;13(5):269-84.

8. Das RN, Chandra TS, Joshi HS, Gurung M, Shrestha N, Shivananda PG. Frequency and susceptibility profile of pathogens causing urinary tract infection at a tertiary care hospital in western Nepal. Singapore Medical J. 2006;47(4):281.

9. Katte HP, Acharya J, Mishra SK, Rijal BP, Pokhrel BM. Bacteriology of urinary tract infection among patients attending Tribhuvan University Teaching Hospital Kathmandu, Nepal. J Nepal Association for Med Laboratory Sci. 2008;9(1).

10. Leung E, Weil DE, Raviglione M, Nakatani $\mathrm{H}$. The WHO policy package to combat antimicrobial resistance. Bulletin of the World Health Organization. 2011;89:390-2.

11. Thakur P, Ghimire P, Rijal KR, Singh GK. Antimicrobial resistance pattern of Escherichia coli isolated from urine samples in patients visiting tertiary health care centre in Eastern Nepal. Sunsari Technical College Journal. 2012;1(1):22-6.

12. Department of Health services, Nepal government ministry of health and population Annual report 2073/2074 (2016/2017).

13. Sharma A, Shrestha S, Upadhyay S, Rijal P. Clinical and Bacteriological profile of urinary tract infection in children at Nepal Medical College Teaching Hospital. Nepal Med Coll J. 2011;13(1):24-6.

14. Raza S, Pandey S, Bhatt CP. Microbiological Analysis of the Urine Isolates in Kathmandu Medical College Teaching Hospital, Kathmandu, Nepal. Kathmandu University Medical Journal. 2011;9(4).

15. Jha N, Bapat SK. A study of sensitivity and resistance of pathogenic microorganisms causing UTI in Kathmandu valley. Kathmandu University Med J. 2005;3(10):123-9.

16. Basnyat B, Pokharel P, Dixit S, Giri S. Antibiotic Use, Its Resistance in Nepal and Recommendations for Action: A Situation Analysis. J Nepal Healt Res Council. 2015;13(30):102-10.

17. WHO. Antimicrobial resistance: Global report on surveillance. 2014;257.

18. Khadka KS, Khadka J, Shrestha P, Tiwari BR. Incidence of Urinary tract infection among the patients visiting Western regional Hospital, Pokhera Nepal. JHAS. 2012;2(1):35-7

19. Bhatt CP, Shrestha B, Khadka S, Swar S, Shah B, Pun K. Etiology of urinary tract infection and drug resistance cases of uropathogenes. J Kathmandu Med College. 2012;1( 2):114-20.

20. Maharjan MN, Mandal KP, Sharma KV. Comparative Study among the Bacterial Causes of Urinary Tract Infection in Diabetic and Non-Diabetic Patients Visiting Alka Hospital, Lalitpur. Ann Clin Med Microbio. 2015;1(2):1006.

21. Sah SK, Regmi R, Upreti AR, Pathak S. Antibiotic resistance patterns and evaluation of treatment in outpatients with urinary tract infections in Nepal. Int J Pharm Sci Res. 2016;7(11):4626-31.

22. Parajuli NP, Maharjan P, Parajuli H, Joshi G, Paudel D, Sayami S, et al. High rates of multidrug resistance among uropathogenic Escherichia coli in children and analyses of ESBL producers from Nepal. Antimicrobial Resistance and Infection Control. 2017;6:9. 
Adhikari and Khanal.: Antibiotic Resistance Patterns and Evaluation of Treatment in Kathmandu, Nepal

23. Shah G, Pokhrel B, Shah AK, Bista PB, Bhattarai A. Bacterial pathogens and antibiotic resistance patterns in children with urinary tract infection admitted at tertiary hospital in Nepal. J Patan Academy Health Sci. 2016;3(2):32-6.

24. Rai GK, Upreti HC, Rai SK, Shah KP, Shrestha RM. Causative agents of urinary tract infections in children and their antibiotic sensitivity pattern: A hospital based study. Nepal Med Coll J. 2008;10(2):86-90.

25. Pokhrel RH, Thapa B, Kafle R, Shah PK, Tribuddharet C. Co-existence of betalactamases in clinical isolates of Escherichia coli from Kathmandu, Nepal. BMC Research Notes. 2014;7:694.
26. Atif M, Sarwar MR, Azeem M, Umer D, Raut A, Ahson M, et al. Assessment of WHO/INRUD core drug use indicators in two tertiary care hospitals of Bahawalpur, Punjab, Pakistan. J Pharm Policy Pract. 2016;9:27.

27. Abidi A, Gupta S, Kansal S, Ramgopal. Prescription auditing and drug utilization pattern in a tertiary care teaching hospital of western UP. Int J Basic Clin Pharmacol. 2012;1:184-90.

28. Ansari S, Nepal HP, Gautam R, Shrestha S, Neupane P, Gurung G, Chapagain ML. Community acquired multidrug resistant clinical isolates of Escherichia coli in a tertiary care center of Nepal: Antimi Resistance Infection Control. 2015;4:15.

Cite this article as: Adhikari P, Khanal DP. Antibiotic Resistance Patterns and Evaluation of Treatment of Inpatient with Urinary Tract Infections in Two Tertiary Care Hospitals at Kathmandu Valley. J Pharm Pract Community Med. 2020;6(1):10-4. 